\title{
Antibacterial Activity of Phenolic Compounds Against the Phytopathogen Xylella fastidiosa
}

\author{
Christina E. Maddox • Lisa M. Laur • \\ Li Tian
}

Received: 29 July 2009/Accepted: 28 August 2009/Published online: 8 October 2009

(c) The Author(s) 2009. This article is published with open access at Springerlink.com

\begin{abstract}
Xylella fastidiosa is a pathogenic bacterium that causes diseases in many crop species, which leads to considerable economic loss. Phenolic compounds (a group of secondary metabolites) are widely distributed in plants and have shown to possess antimicrobial properties. The antiXylella activity of 12 phenolic compounds, representing phenolic acid, coumarin, stilbene and flavonoid, was evaluated using an in vitro agar dilution assay. Overall, these phenolic compounds were effective in inhibiting X. fastidiosa growth, as indicated by low minimum inhibitory concentrations (MICs). In addition, phenolic compounds with different structural features exhibited different anti-Xylella capacities. Particularly, catechol, caffeic acid and resveratrol showed strong anti-Xylella activities. Differential response to phenolic compounds was observed among $X$. fastidiosa strains isolated from grape and almond. Elucidation of secondary metabolite-based host resistance to $X$. fastidiosa will have broad implication in combating $X$. fastidiosa-caused plant diseases. It will facilitate future production of plants with improved disease resistance properties through genetic engineering or traditional breeding approaches and will significantly improve crop yield.
\end{abstract}

\section{Introduction}

Xylella fastidiosa is a gram-negative bacterium that causes serious diseases in many economically important crops, such as Pierce's disease in grape (PD), variegated chlorosis

C. E. Maddox · L. M. Laur · L. Tian ( $₫)$

Department of Plant Sciences, University of California, Davis,

Mail Stop 3, 221 Asmundson Hall, One Shields Ave, Davis,

CA 95616, USA

e-mail: 1tian@ucdavis.edu in citrus (CVC) and leaf scorch in almond (ALS) [14]. X. fastidiosa colonizes exclusively in the xylem vessels (conductive tissue) of infected plants, and it is transmitted from diseased to healthy plants by insects that feed on xylem fluid (sap). Colonization of $X$. fastidiosa in the xylem vessel blocks water and nutrient transport from root to shoot, which results in disease and death of the infected plants. Axenic culture of $X$. fastidiosa can be maintained in vitro in customized bacterial growth media [6]. Although $X$. fastidiosa proliferates rapidly in planta, it is nutritionally fastidious and grows slowly on culture media [6].

Economic loss due to $X$. fastidiosa-caused crop diseases is estimated to be billions of dollars each year. To effectively control the occurrence and spread of X. fastidiosacaused crop diseases, research has been conducted in three major areas: limiting insect vectors that transmit the bacterial pathogen, elucidating the signalling events between the bacterial pathogen and host plants and understanding the host inhibition of bacterial growth. Because X. fastidiosa colonization in plants is limited to the xylems, particular attention has been given to xylem-localized small molecules that can potentially inhibit the growth and movement of $X$. fastidiosa. These small molecules in grapevine xylem sap include amino acids, peptides, organic acids and low-molecular weight secondary metabolites. A recent study has shown that several strains of $X$. fastidiosa were sensitive to antimicrobial peptides when assayed in vitro [13]. However, these peptides were either synthetic or isolated from seeds of ornamental plant, bacteria, xenopus or human neutrophils. They are not known to be present in host plants of $X$. fastidiosa.

Low-molecular weight secondary metabolites are essential for plant disease resistance. Accumulation of certain plant secondary metabolites is induced upon pathogen attack and these metabolites are referred to as 
phytoalexins. Some phytoalexins have broad spectrum activities against a wide range of pathogens, while others target specific pathogens. Phenolics are a class of plant secondary metabolites that contain one or more hydroxy derivatives of benzene rings. Phenolics are widely distributed in plants and are used for defensive functions in many plant species [4]. Phenolics in plants are mainly synthesized from the phenylpropanoid pathway. In vitro antimicrobial activities of the phenylpropanoid pathway intermediates, including $p$-coumaric acid, caffeic acid, ferulic acid and sinapic acid, and pathway derivatives, including flavonoid aglycones and glycosides, have been demonstrated experimentally [2, 7]. Phenolic compounds with less complex structures, such as catechol and coumarin, have also shown to exhibit bactericidal and fungicidal activities [5]. Increased accumulation of phenolic phytoalexins in plants can promote host defense against pathogens. One outstanding example is the resistance of grape phenolic stilbenes to fungal colonization [12]. Ectopic expression of a grape stilbene synthase gene in tobacco led to increased resistance of transgenic tobacco to infection by Botrytis cinerea [10].

To determine whether phenolic compounds can inhibit $X$. fastidiosa growth in vitro, we have conducted an agar plate dilution assay on a group of phenolic compounds that were previously reported as having antimicrobial activities. We here report the inhibitory effects of 12 phenolic compounds towards growth of four $X$. fastidiosa strains that use grape and almond as host.

\section{Materials and Methods}

\section{Strains and Growth Conditions}

X. fastidiosa strains Temecula, Conn Creek, Dixon and Tulare were kindly provided by Drs. Bruce Kirkpatrick (University of California, Davis) and Rodrigo Almeida (University of California, Berkeley) (Table 1). The $X$. fastidiosa strains were maintained on PD3 (Temecula and Conn Creek) and PW (Dixon and Tulare) agar at $28^{\circ} \mathrm{C}$. PD3 and PW growth media were prepared as previously described [6]. For long-term storage, glycerol stocks of $X$. fastidiosa cells were prepared in the corresponding growth media with a final glycerol concentration of $12 \%$. The bacterial glycerol stocks were quickly frozen in liquid nitrogen and stored at $-80^{\circ} \mathrm{C}$.

Phenolic Stock Solutions and Anti-Xylella Activity Assay

Caffeic acid, catechin, $p$-coumaric acid, resveratrol, rutin and sinapic acid were purchased from Sigma (St. Louis,
Table 1 Xylella fastidiosa strains used in this study

\begin{tabular}{lll}
\hline Strain & Host & References \\
\hline Temecula & Grape & {$[8]$} \\
Conn Creek & Grape & {$[11]$} \\
Dixon & Almond & {$[15]$} \\
Tulare & Almond & {$[1]$} \\
\hline
\end{tabular}

MO). Catechol, coumarin, ferulic acid, gallic acid, naringenin and quercetin were purchased from Acros Organics (Geel, Belgium). Catechol, coumarin and gallic acid were dissolved in deionized water at room temperature to a final concentration of $16 \mathrm{mM}$. Caffeic acid, $p$-coumaric acid and ferulic acid were dissolved in warm deionized water $\left(80-90^{\circ} \mathrm{C}\right)$ at $16 \mathrm{mM}$. All stock solutions prepared in water were sterilized by passing through $0.2 \mu \mathrm{m}$ HT Tuffryn membrane syringe filters (PALL Life Sciences, East Hills, NY).

Catechin, naringenin, quercetin, resveratrol, rutin and sinapic acid are either insoluble or only slightly soluble in water. For stock solution preparations, these compounds were dissolved in ethanol or dimethyl sulfoxide (DMSO). To determine whether ethanol or DMSO inhibits X. fastidiosa growth, control experiments were carried out using culture media supplemented with $5 \%$ ethanol or $0.7 \%$ DMSO, which are equivalent to the maximum concentration of solvents used in the anti-Xylella activity assay. Total inhibition of $X$. fastidiosa growth was observed when $5 \%$ ethanol was added to the culture medium, while $0.7 \%$ DMSO did not impact $X$. fastidiosa cell growth. Catechin, naringenin, quercetin, resveratrol, rutin and sinapic acid were therefore dissolved in DMSO to a final concentration of $320 \mathrm{mM}$ and filtered through DMSO-safe nylon membrane syringe filters (PALL Life Sciences, East Hills, NY). Phenolic stock solutions were diluted in deionized water or DMSO and were added to the PD3 or PW media before pouring into plates. The final concentrations of phenolic compounds in the growth media were $10 \mu \mathrm{M}, 20 \mu \mathrm{M}$, $40 \mu \mathrm{M}, 80 \mu \mathrm{M}, 100 \mu \mathrm{M}, 200 \mu \mathrm{M}, 400 \mu \mathrm{M}, 800 \mu \mathrm{M}$, $1 \mathrm{mM}, 2 \mathrm{mM}, 4 \mathrm{mM}$ and $8 \mathrm{mM}$.

$X$. fastidiosa strains were grown in liquid PD3 or PW media as previously described [9] and were adjusted to a final concentration of $10^{5}$ cells $\mathrm{ml}^{-1}$ prior to plating. Ten microlitres of $X$. fastidiosa inoculum was applied to the PD3 or PW agar plate with or without phenolic supplements. The agar plates were wrapped with Parafilm and incubated at $28^{\circ} \mathrm{C}$. The minimum inhibitory concentration (MIC) for each phenolic compound was determined after 7 days incubation for Temecula and Conn Creek strains, and after 14 days incubation for Dixon and Tulare strains. MIC was defined as the lowest chemical concentration that yields no colony growth on PD3 or PW agar plates. PD3 
and PW plates without added phenolic compounds were used as negative controls. Chloramphenicol at $1 \mathrm{~g} \mathrm{l}^{-1}$ final concentration was used as positive control for inhibition of $X$. fastidiosa growth. In each experiment (with freshly grown $X$. fastidiosa inoculum), anti-Xylella activity assays were performed in duplicate for each phenolic compound at different concentrations. Every experiment was repeated two to four times.

\section{Results and Discussion}

\section{Anti-Xylella Activity Assay}

An agar disc diffusion method has been commonly used for antimicrobial susceptibility testing [3]. The reliability of this method depends on growth of the bacteria and diffusion of the antimicrobial chemicals. It is suitable for testing rapidly growing bacteria. $X$. fastidiosa grows slowly on culture medium and has stringent requirement for nutrients. The agar disc diffusion assay is not appropriate for in vitro examination of anti-Xylella activity of phenolic compounds. Alternatively, an agar plate dilution method was used successfully in determining the inhibitory effect of antimicrobial peptides towards X. fastidiosa growth [13]. We have adopted this method for the in vitro anti-Xylella activity assay.

Anti-Xylella activity assays were carried out on phenolic compounds that are associated with antimicrobial activities and are present in plants (Fig. 1). Phenolic stock solutions were added to the culture media with final concentration ranging from $10 \mu \mathrm{M}$ to $8 \mathrm{mM}$. Consistent with previous reports, grape strains grew more rapidly and colonies were visible after 5 days of incubation. In
Fig. 1 Chemical structures of phenolic compounds that are evaluated in this study

\section{Simple phenolics}<smiles>O=c1ccc2ccccc2o1</smiles>

Coumarin<smiles>Oc1ccccc1O</smiles>

Catechol

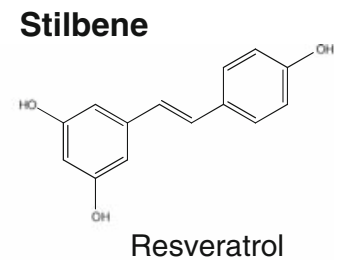

Resveratrol

Phenolic acids

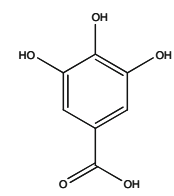

Gallic acid

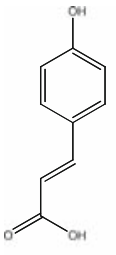

p-coumaric acid

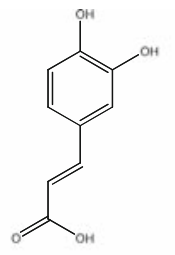

Caffeic acid

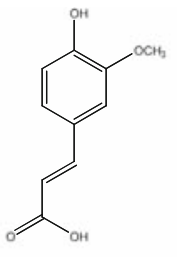

Ferulic acid

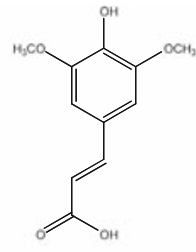

Sinapic acid

\section{Flavonoids}<smiles>Cc1ccc(C2Nc3cc(I)cc(I)c3CC(C)C2c2cccc(C)c2)cc1</smiles>

Catechin

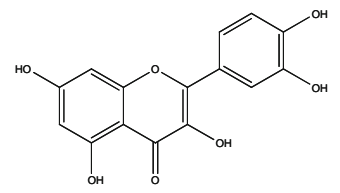

Quercetin<smiles>Cc1ccc(C2CC(C)c3c(C)cc(C)cc3N2)cc1</smiles>

Naringenin

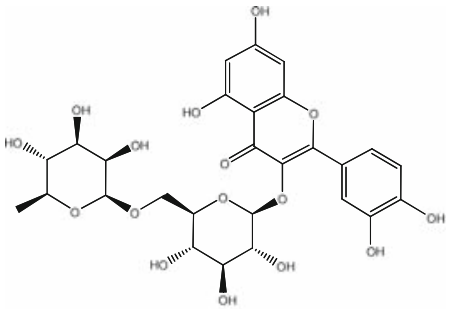

Rutin (Quercetin 3-rutinoside) 
contrast, almond strains grew more slowly and colonies were visible after 10 days of incubation. The MIC for phenolic compounds was determined after 7 days of incubation for grape strains and after 14 days of incubation for almond strains. Consistent results were produced for each compound in the repeated experiments. The MICs of phenolic compounds against grape and almond $X$. fastidiosa strains are summarized in Tables 2 and 3.

Structure Anti-Xylella Activity Relationship of Phenolic Compounds

Antibacterial activities of plant phenolics and plant extracts were evaluated recently against a wide range of bacteria $[17,18]$. However, $X$. fastidiosa was not a target in these studies. In addition, the previous work focused on polyphenolic compounds (contain more than one benzene ring) with more complex structures. The phenolics gallic acid, caffeic acid, catechol, rutin and resveratrol were tested in both previous investigation and our current studies (Tables 2 and 3, [18]). Our results showed that X. fastidiosa growth is more susceptible to the above-mentioned phenolic compounds than the gram-positive and gramnegative bacteria tested in [18].

Phenolic acids with methoxy $\left(-\mathrm{OCH}_{3}\right)$ substitutions (ferulic acid and sinapic acid) are less effective in inhibiting $X$. fastidiosa growth (Table 2). Although the di- and tri-hydroxyl phenolic acids, caffeic acid and gallic acid, are more active than the mono-hydroxyl phenolic acid, $p$-coumaric acid, there is no direct correlation between the number of hydroxy $(-\mathrm{OH})$ substitutions on the ring structure and the anti-Xylella activity of the compounds (Table 2). Overall, the presence of hydroxyl $(-\mathrm{OH})$ group(s) at the meta-position of the benzene ring structure appears to enhance the anti-Xylella activity of the phenolic acid (Fig. 1; Table 2).

Different subgroups of flavonoid compounds, including flavanone (naringenin), flavan-3-ol (catechin), flavonol aglycone (quercetin) and flavonol glycoside (rutin), were tested for anti-Xylella activities. Compared to phenolic acids, flavonoids generally have strong inhibitory activities against $X$. fastidiosa growth, except for rutin (quercetin glycoside), which is less active than the corresponding aglycone quercetin (Fig. 1; Table 3). Similar to flavonoids $\left(\mathrm{C}_{6}+\mathrm{C}_{3}+\mathrm{C}_{6}\right)$, stilbenes (such as resveratrol) are also derived from phenylalanine. However, due to the difference in condensation reactions, the core skeleton for stilbenes is $\mathrm{C}_{6}+\mathrm{C}_{2}+\mathrm{C}_{6}$. Resveratrol exhibited very strong inhibitory activities $(\mathrm{MIC}=200 \mu \mathrm{M})$ towards all four $X$. fastidiosa strains.

Catechol and coumarin (with a core structure of $\mathrm{C}_{6}+\mathrm{C}_{3}$ ) are phenolic compounds with simple structures. Of all the phenolic compounds tested, catechol has the strongest anti-Xylella activity. We tested a representative of coumarins that has no structural modifications and found that it is less effective in inhibiting $X$. fastidiosa growth than the flavonoid aglycones (Table 3). Coumarins are present in plants in both aglycone and glycosylated forms.

Recently, anti-Xylella activities of several plant secondary metabolites, including flavonoids, terpenoids,

Table 2 Minimum inhibitory concentration (MIC) of phenolic acids against Xylella fastidiosa strains

\begin{tabular}{lllccc}
\hline \multirow{2}{*}{ Strain } & MIC & & & \\
\cline { 2 - 6 } & $p$-Coumaric acid $(\mu \mathrm{M})$ & Caffeic acid $(\mu \mathrm{M})$ & Ferulic acid $(\mu \mathrm{M})$ & Sinapic acid $(\mu \mathrm{M})$ & Gallic acid $(\mu \mathrm{M})$ \\
\hline Temecula & 800 & 200 & 800 & 2000 & 200 \\
Conn Creek & 400 & 200 & 2000 & 2000 & 200 \\
Dixon & 400 & 200 & 800 & 800 & 400 \\
Tulare & 400 & 200 & 800 & 800 & 400 \\
\hline
\end{tabular}

The final concentrations of phenolic acids ranged from $10 \mu \mathrm{M}$ to $8 \mathrm{mM}$. Anti-Xylella activity assays were performed in duplicate each time and every experiment was repeated two to four times

Table 3 Minimum inhibitory concentration (MIC) of various phenolic compounds against Xylella fastidiosa strains

\begin{tabular}{llllllll}
\hline & MIC & & & & \\
\cline { 2 - 7 } Strain & Coumarin $(\mu \mathrm{M})$ & Catechol $(\mu \mathrm{M})$ & Naringenin $(\mu \mathrm{M})$ & Quercetin $(\mu \mathrm{M})$ & Rutin $(\mu \mathrm{M})$ & Catechin $(\mu \mathrm{M})$ & Resveratrol $(\mu \mathrm{M})$ \\
\hline Temecula & 800 & 100 & 200 & 200 & 800 & 400 & 200 \\
Conn Creek & 2000 & 200 & 200 & 200 & 800 & 400 & 200 \\
Dixon & 400 & 200 & 400 & 400 & 800 & 200 & 200 \\
Tulare & 800 & 100 & 400 & 200 & 400 & 200 & 200 \\
\hline
\end{tabular}

The final concentrations of phenolic compounds ranged from $10 \mu \mathrm{M}$ to $8 \mathrm{mM}$. Anti-Xylella activity assays were performed in duplicate each time and every experiment was repeated two to four times 
coumarins, phenolic acids and alkaloids, were tested against a $X$. fastidiosa strain $(9 \mathrm{a} 5 \mathrm{c})$ that causes CVC in sweet orange (Citrus sinensis) [16]. The MIC of these metabolites generally ranges from 2 to $8 \mathrm{mM}$ [16]. Most of the secondary metabolites investigated by Ribeiro et al. [16] are not present in grapevine and therefore were not selected as test compounds in our study. However, it is notable that catechin inhibits $X$. fastidiosa growth at $3.4 \mathrm{mM}$ for the citrus strain and at no more than $400 \mu \mathrm{M}$ for the grapevine strains (Table 3; [16]).

\section{Differential Strain Response Towards Phenolic Compounds}

$X$. fastidiosa causes diseases in different crop species, such as grape and almond. Though previously considered to be the same strains, genetic analysis using both repetitive extragenic palindromic element (REP)-PCR and random amplified polymorphic DNA (RAPD)-PCR indicated that genetic variations exist among grape and almond strains [11]. Furthermore, in vitro culture experiments showed that certain almond strains did not grow on PD3 medium, which is commonly used for culturing of grape strains [1]. These results together suggest that distinct groups of almond and grape strains likely exist. Grape strains Temecula and Conn Creek and the almond strain Tulare grow on PD3 medium and can infect both grape and almond. However, the almond strain Dixon cannot grow on PD3 medium and is avirulent to grape [1]. Both Dixon and Tulare strains can be cultured on PW medium.

To determine whether the inherent genetic variations in grape and almond strains affect their colonization in response to phenolic compounds, grape strains Temecula and Conn Creek were plated on PD3 media supplemented with different concentrations of phenolic compounds; almond strains Conn creek and Tulare were cultured on PW media with added phenolic compounds. Differential responses to phenolic compounds were found between the grape and almond strains (Tables 2 and 3). Temecula and Conn creek are closely related grape strains that show similar rate of colonization in host plants. Temecula was isolated from Riverside, Southern California, while Conn Creek was isolated from Napa Valley, Northern California. Interestingly, differential responses were also observed between these two closely related grape strains (Tables 2 and 3).

\section{Concluding Remarks}

Our studies showed that low-molecular weight plant secondary metabolites, specifically phenolic compounds, can inhibit $X$. fastidiosa growth in vitro. However, the mechanism for $X$. fastidiosa growth inhibition by phenolic compounds is still unknown. Phenolic compounds are present in a wide range of plants, some of which are hosts of $X$. fastidiosa. Crops with improved resistance to $X$. fastidiosa-caused diseases can potentially be produced by increasing the endogenous anti-Xylella phenolic concentration (more acceptable to the general public), instead of introducing novel antibacterial compounds. In addition, biochemical markers can be developed for breeding of disease-resistant crop cultivars by determining the concentration of endogenous anti-Xylella phenolics.

Acknowledgements We thank Drs. Bruce Kirkpatrick, Rodrigo Almeida and Nabil Killiny for providing various $X$. fastidiosa strains. We also thank Tanja Vogel for helpful advice on growing X. fastidiosa strains and Elianna Goldstein for critical reading of the manuscript.

Open Access This article is distributed under the terms of the Creative Commons Attribution Noncommercial License which permits any noncommercial use, distribution, and reproduction in any medium, provided the original author(s) and source are credited.

\section{References}

1. Almeida RP, Purcell AH (2003) Biological traits of Xylella fastidiosa strains from grapes and almonds. Appl Environ Microbiol 69:7447-7452

2. Barber MS, McConnell VS, DeCaux BS (2000) Antimicrobial intermediates of the general phenylpropanoid and lignin specific pathways. Phytochemistry 54:53-56

3. Bauer A, Kirby W, Sherris J et al (1966) Antibiotic susceptibility testing by a standardized single disk method. Am J Clin Pathol 45:493-496

4. Boudet A (2006) Evolution and current status of research in phenolic compounds. Phytochemistry 68:2722-2735

5. Cowan M (1999) Plant products as antimicrobial agents. Clin Microbiol Rev 12:564-582

6. Davis MJ, French WJ, Schaad NW (1981) Axenic culture of the bacteria associated with phony disease of peach and plum leaf scald. Curr Microbiol 6:309-314

7. Dixon RA (2001) Natural products and plant disease resistance. Nature 411:843-847

8. Feil H, Purcell AH (2001) Temperature-dependent growth and survival of Xylella fastidiosa in vitro and in potted grapevines. Plant Dis 85:1230-1234

9. Guilhabert MR, Hoffman LM, Mills DA et al (2001) Transposon mutagenesis of Xylella fastidiosa by electroporation of Tn5 synaptic complexes. Mol Plant Microbe Interact 14:701-706

10. Hain R, Reif HJ, Krause E et al (1993) Disease resistance results from foreign phytoalexin expression in a novel plant. Nature 361:153-156

11. Henderson M, Purcell AH, Chen D et al (2001) Genetic diversity of Pierce's disease strains and other pathotype of Xylella fastidiosa. Appl Environ Microbiol 67:895-903

12. Jeandet P, Douillet-Breuil AC, Bessis R et al (2002) Phytoalexins from the Vitaceae: biosynthesis, phytoalexin gene expression in transgenic plants, antifungal activity, and metabolism. J Agric Food Chem 50:2731-2741

13. Kuzina LV, Miller TA, Cooksey DA (2006) In vitro activities of antibiotics and antimicrobial peptides against the plant 
pathogenic bacterium Xylella fastidiosa. Lett Appl Microbiol 42:514-520

14. Purcell AH, Hopkins DL (1996) Fastidious xylem-limited bacterial plant pathogens. Annu Rev Phytopathol 34:131-151

15. Purcell A, Saunders S, Hendson M et al (1999) Causal role of Xylella fastidiosa in oleander leaf scorch disease. Phytopathology 89:53-58

16. Ribeiro AB, Abdelnur PV, Garcia CF et al (2008) Chemical characterization of Citrus sinensis grafted on $C$. limonia and the effect of some isolated compounds on the growth of Xylella fastidiosa. J Agric Food Chem 56:7815-7822

17. Taguri T, Tanaka T, Kouno I (2004) Antimicrobial activity of 10 different plant polyphenols against bacteria causing food-borne disease. Biol Pharm Bull 27:1965-1969

18. Taguri T, Tanaka T, Kouno I (2006) Antibacterial spectrum of plant polyphenols and extracts depending upon hydroxyphenyl structure. Biol Pharm Bull 29:2226-2235 